\title{
Effect of Preoperative Instructions for Mothers on Selected Postoperative Outcomes Among their Children with Hypospadias
}

\author{
WALAA M. KAMEL, M.Sc.*; SOHEIR A. MOHAMED, D.N.Sc.*; MARWA A. IBRAHEIM, D.N.Sc.* and \\ MOHAMED H. AHMED, M.D.**
}

The Departments of Pediatric Nursing, Faculty of Nursing* and Pediatric Surgery**, Faculty of Medicine, Cairo University, Egypt

\begin{abstract}
Background: Hypospadias is the most common birth defect among children affecting the penis characterized by ventral position of urethral meatus in which caused by arrest of normal development of the urethra.

Aim of Study: To evaluate the effect of preoperative instructions for mothers on selected postoperative outcomes among their children with hypospadias.

Subjects and Methods: A quasi-experimental research design (Pre-Posttest) was used to achieve the aim of the current study. A convenient sample of 60 mothers having male children undergoing surgical repair of hypospadias participated in the current study, divided into two equal groups: 30 as a control group and 30 as a study group who were subject to the preoperative instructions. The setting was in-patient pediatric surgical department at Cairo University Specialized Pediatric Hospital (CUSPH). The required data was collected through: 1- Structured interview (questionnaire); 2- Mothers' knowledge and reported practice assessment sheet (preposttest) and 3- Postoperative outcomes assessment record.

Results: The study's results revealed that, children in the study group exposed to less early postoperative complications such as (bleeding, wound dehiscence, urinary obstruction and urinary catheter fall) than children in the control group. Late postoperative complications (fistula, meatal stenosis, urethral obstruction and infection) occurred in children in the study group less than those in the control group. Children in the study group had appropriate cosmetic appearance of the penis and functional outcome than children in the control group.

Conclusion: The current study concluded that children whom mothers received the preoperative instructions about hypospadias had improved outcomes in relation to less complications, higher cosmetic and functional outcomes than children in the control group. Recommendation: It was recommended that provision of pre and post-operative care of children undergoing hypospadias repair is mandatory to achieve satisfactory postoperative outcomes.
\end{abstract}

Key Words: Hypospadias - Preoperative instructions - Postoperative outcomes - Children.

Correspondence to: Dr. Walaa M. Kamel, The Department of Pediatric Nursing, Faculty of Nursing, Cairo University, Egypt

\section{Introduction}

HYPOSPADIAS is traditionally defined by the anatomical position of the urethral meatus on the ventral surface of the penis. This results from incomplete fusion of the urethral folds of the urethral spongiosum during intrauterine development and can range in position from the glans corona up to the perineum. Aside from variations in the localization of the urethral opening, hypospadias can also present with atypical shape of the urethral opening, of the glans, and of penile skin, various degrees of penile curvature, unilateral or bilateral cryptorchidism. Severe hypospadias cases can also present with penile scrotal transposition and/or enlarged prostatic utricle. In severe cases, clinical protocols for the management of intersexuality are commonly deployed [1].

Hypospadias occurs in approximately 1 of every 150 to 300 male births and may arise more frequently in developing countries. While not life threatening and concealed by normal clothing, the potential consequences of uncorrected hypospadias include social stigmatization and urinary or sexual dysfunction [2]. Hypospadias is one of the most common congenital malformations, with an incidence of 1 in 125 boys [3]

Hypospadias classified into: $70 \%$ anterior hypospadias (distal or first-degree) can be divided into hypospadias sine (ventral curvature of the penis with a normally-placed urethral meatus), glandular (mildest form involving extension of the urethral meatus down to the ventral part of the glans), and sub-coronal (urethral meatus next to the coronal sulcus). Fifteen percent middle hypospadias (second-degree) midline placement of the urethral meatus in various positions on the ventral surface of the penile shaft, can be divided into (distal 
penile, mid-shaft, and proximal penile). Fifteen percent for posterior hypospadias (proximal or third-degree) can be divided into penoscrotal urethral meatus (located where the base of the penis and the scrotum meet), scrotal (urethral meatus located in the scrotum), and perineal (urethral meatus positioned below the scrotum and on the perineum) [4].

Operating hypospadias done at the age of 6-12 months. In developed countries, children are taken to the hospital at a pediatric age suitable for surgery. However, in developing countries, home births are still common place, mostly with the parents lacking awareness of congenital anomalies [5]. Illiteracy and ignorance are among the most important reasons why children with hypospadias present late to the hospital, mostly after the age of 2 years, and a significant number even in late childhood or as adults [6].

Hypospadias is usually surgically corrected. Goals of repair include cosmetic appearance of the external genitalia with as normal appearance as possible, restoration of normal urinary function and normal sexual function as an adult [7]. The aim of the surgeon is to achieve these goals with lowest complication rate. The best functional result may be defined clearly as an adequately forward directed stream when standing and normal coitus. On the other hand, definition of perfect cosmetic appearance is a vertical slit-like meatus on the tip of a normal looking glans with a mucosalcollar around, a straight penis in the absence of unpleasant scar tissue is considered to be successful and satisfactory [8]

Despite multiple techniques and decades of research, the management of hypospadias remains one the most challenging problems in pediatric urology. Postoperative outcomes are variable and difficult to interpret due to important discrepancies in pre-operative child characteristics, operative techniques, follow-up duration and the surgeon's outcome perception. As well as the child's quality of life and perception of the repair importance, this should ultimately drive management [9] .

The rate of reported surgical complications varies, ranging from $11.8 \%$ to $61.5 \%$ [10]. While, [8] examined all children on postoperative first week, at 1 and 6 months then found that early and late complications such as bleeding, hematoma, surgical site infection, urethra-cutaneous fistula, meatal stenosis, meatal regression, and glanular dehiscence, previous hypospadias repairs, and secondary surgical interventions were evaluated and were the most common postoperative complications.

Proper assessment and preparation for surgery is a key to success for positive surgical outcomes and family satisfaction. Assessing and teaching children on the day of elective surgery is often not feasible or appropriate. It is important to reach out to children days before surgery for assessment and education and to allay the anxiety which is so common in children and parents [11]. Advances in perioperative care and decreased operative morbidity has resulted in the migration of inpatientprocedures to the outpatient setting [12].

Goals of nursing management are to assist in collaborative identification of the defect, promote parental understanding, prevent potential complications and promote a normal voiding pattern [13] It is important for the nurse to address parents' concerns at the time of birth. Preoperative teaching can relieve some of anxiety about the appearance and functioning of the penis. The male infant returns from surgery with the penis wrapped in a pressure dressing and a urethral stent in place to keep the new urethral canal open. Discharge teaching should include instructions for parents about: Care of the repaired area (dressing, stent and prevent adhesion), medications (antibiotics, pain management), hygienic care, diet and activities [14]

\section{Significance of the study:}

There was an increase in the incidence of male children undergoing surgical repair of hypospadias from 225 cases out of 852 case were undergoing urological surgical operations in 2012 this number increased to 232 case out of 889 case were undergoing urological operations in 2013. Through clinical observation, it was detected that children with hypospadias undergoing surgical repair were at high risk for many complications related to the lack of awareness and inadequate care given by the mothers of these children. Despite the importance of accurate care needed for these children as hypospadias has lifelong psychosocial effects on children, there is a great neglect of explaining the condition for mothers and guiding them to what to do [15].

In Egypt, there are scarce studies conducted in the field of nursing care of children with genitourinary surgical disorders in particular those children with hypospadias. Hence, the current study was under taken to evaluate the effect of preoperative instructions provided for the mothers of children 
with hypospadias on the selected postoperative outcomes. Hopefully, results of the present study will help in improving the mother's knowledge regarding care of children having hypospadias. As well as providing guidance and recommendations that should be reflected in pediatric nursing education and providing evidenced based data that can develop nursing practice and research in the field of pediatric surgery nursing.

\section{Research Hypotheses:}

- Children of mothers who will receive the preoperative instructions will have less postoperative complications than children in the control group.

- Children of mothers who will receive the preoperative instructions will have improved urinary functional outcome than children in the control group.

- Children of mothers who will receive the preoperative instructions will have appropriate cosmetic appearance of the penis after surgery than children in the control group.

\section{Aim of study:}

The aim of the current study was to evaluate the effect of preoperative instructions for mothers on selected postoperative outcomes among their children with hypospadias.

\section{Subjects and Methods}

Research design:

Quasi-experimental design (Pre-Posttest) was utilized to carry out this study.

\section{Setting:}

The current study was conducted at in-patient pediatric surgical department at CUSPH. At the period started from 10/2015 to 6/2016.

\section{Study subject:}

A convenient sample of 60 mothers having male children undergoing surgical repair of hypospadias was participated in the current study. Those participants divided into two equal groups: 30 as a control group who received the hospital routine care and 30 as a study group who were subjected to the preoperative instructions.

\section{Inclusion criteria:}

- All male children who will have one stage surgical repair of hypospadias (free from chor-dee).

- Children aged 1-5 years.
- Mother should be the primary caregiver that accompanied with the child in the hospital.

\section{Exclusion criteria:}

Children with other genitourinary congenital anomalies such as (Inguinal hernia, undescended testis and bladder extrophy) will be excluded from the study.

\section{Tools for data collection:}

The required data was collected through the following tools:

1-Structured interview (questionnaire): It was developed by the research investigator in Arabic language after reviewing the related literature which contain thirty three (33) questions and consisted of two parts:

Part I: It involved seven (7) questions related to personal data about mothers as: age, level of education, occupation, place of residence, number of children, consanguinity... etc. It also includes six (6) questions about characteristics of children such as age, weight, birth order, etc. This part also contained five (5) questions about child's diagnosis, time of diagnosis, family history, ... etc.

Part II: Preoperative Recording Sheet: It consisted of fifteen (15) questions to assess the severity of hypospadias done by the assigned pediatric surgeon and the research investigator. It included items to assess vital signs, laboratory investigations, diagnostic tests, site of operation and preoperative preparations also assessed.

2- Mothers' knowledge and reported practice assessment Sheet (Pre-Posttest): It involved thirty three (33) questions developed by the research investigator to assess mothers' knowledge and reported practice regarding care of their children undergoing surgical repair of hypospadias such as: meaning of hypospadias, preoperative and postoperative care, how to remove the surgical dressing, care of the urethral stent if present, diet, hygiene and child activities ...... etc.

3-Postoperative Outcomes Assessment Record: It was developed by the research investigator for the purpose of follow up of all participants (study and control group) through one week starting from the first day postoperative until week postoperatively. The recording sheet divided into three sections:

a- At the first postoperative day (immediate) to evaluate early complications such as bleeding and fever. 
b- At the third day after surgical repair (at the time first dressing removal) to evaluate early complications such as fever, bruising, graft necrosis, wound dehiscence, urinary obstruction, burning on urination and falling of the urinary catheter or stent.

c- After first week from surgical repair, three items were evaluated; the first was late complications such as fistula, meatal stenosis, urethral obstruction, and infection. The second one was the postoperative functional outcome through assessing the stream of urination (one direction or interrupted). The third one was cosmetic appearance by assessing the children' penis postoperatively and comparing its appearance with normal appearance of penis made by assessing shape of glans, shape of meatus and shape of penile skin and straight penile axis.

\section{Scoring system:}

For mothers' knowledge and reported practice; each correct response/activities will take one score, and the wrong response or the not known will take zero score. The total score will be converted to $100 \%$, and then categorized as following: The total score less than $50 \%$ was considered as unsatisfactory while score of $50 \%$ and more was considered as satisfactory level.

\section{Field work:}

Before conducting the study an official permission was obtained from the directors of Cairo University Children Hospital and approval from the head of pediatric surgery department also was obtained. The research investigator introduced self to children' mothers fulfilling study criteria and explained the aim of the study. At the day of surgical operation, the written informed consent was obtained from each mother after complete description of the purpose and nature of the study then the research investigator filled the questionnaire sheet (tool 1, part I) from children' mother through structured interview on an individual bases to collect the personal data about mothers and their children in both study and control groups.

The severity of hypospadias of children in both groups was assessed by the assigned pediatric surgeon and the research investigator using the preoperative recording sheet (tool1, part 2). It also includes items to assess vital signs, laboratory investigations, diagnostic tests, site of operation and preoperative preparations also assessed. Then all mothers exposed to the pretest sheet (tool 2).
Preoperative nursing instructions were explained to the mothers in the study group at the day of operation through two educational sessions each session was took about 30-45 minutes on individual basis and sometimes for a group of mothers ranged from 2 to 5 mothers.

Arabic illustrated nursing instructions about appropriate postoperative care for the child after surgical repair of hypospadias was prepared by the research investigator and it was given and explained to the mothers in the study group. It include simple information about hypospadias, care of the reconstructed area (dressing, stent and prevention of adhesion), medications, hygienic care, diet, fluid intake and activities; aided by an instructional illustrated Arabic booklet and re-demonstration of practice on a doll.

At the day of surgical operation, the research investigator filled the preoperative recording sheet (tool 1, part II) for children in the study and control groups and assess the site of operation before and after the surgical repair then it was reassessed again at the third day of surgical repair. Also at the third day of surgical operation, mothers' knowledge and their reported practice were evaluated through posttest (tool 2). On the same day, the research investigator observed and recorded the early postoperative complications, then after one week from surgical operation, the late postoperative complications, the functional and cosmetic outcomes were observed and recorded through postoperative outcomes assessment record (tool 3). Data collection was conducted over eight months period extending from October 2015 till May 2016.

\section{Validity and Reliability:}

Data collection tools of the study were submitted to 5 experts in the field of pediatric surgery and pediatric surgery nursing to test the content validity. The experts' agreed on the content of the tools, but recommended minor language changes that would make the information clearer and more precise. The suggested changes were made. Regarding reliability, the Cormack's alpha coefficients' was done between questions and it was 0.77 .

\section{Pilot study:}

The pilot study was carried out on (6) mothers of children undergoing surgical repair of hypospadias to test study tools in terms of its clarity, applicability and time required to fulfill it. The needed modifications were done, and then the final format was developed. The pilot study participants were excluded from the total sample. 


\section{Administrative and ethical consideration:}

A primary approval was obtained from the research ethical committee in the faculty of nursing, Cairo University. A written informed consent obtained by the research investigator after taking acceptance from the research ethical committee. The written informed consent was obtained from the mothers of children after complete description of the purpose and nature of the study in order to obtain their acceptance as well as to gain their cooperation. Children and their mothers were informed that participation in the study was voluntary. Confidentiality assured to each child and their mothers. For research ethical consideration data collected firstly from the control group.

\section{Statistical design:}

The collected data tabulated, and summarized. A statistical package for social studies (SPSS) version 20 was used for statistical analysis of data. Data was computerized and analyzed using appropriate descriptive and inferential statistical tests. Qualitative data were expressed as frequency and percentage. A comparison between qualitative variables carried out by using parametric Chi square test. Comparison of means was performed using paired-sample $t$-test. Correlation among variables was done using Pearson correlation coefficient. Level of significance at $p<0.05,0.001$ were used as the cut of value for statistical significance.

\section{Results}

The current study results revealed that $40 \%$ of mothers in both groups their age ranged from 25 to less than 30 years. Half of mothers $(50 \%)$ in the study group were not read or write while $36.7 \%$ of mothers in the control group had basic education. The majority of mothers in the study group $(87.7 \%)$ were working outside home. On the other hand, all mothers in the control group $(100 \%)$ were house wives. There was no statistically significant difference between mothers in both groups regarding age and level of education $\left(\mathrm{X}^{2}=23.067, p=.574 \&\right.$ $\mathrm{X}^{2}=33.576, p=.117$ respectively).

Fig. (1) illustrated that a relatively high percentage of non-consanguineous marriage in both groups $(56.7 \%, 63.3 \%$, respectively). There was no statistically significant difference between mothers in both groups regarding consanguinity $\left(\mathrm{X}_{2}=\right.$ $0.32, p=.858$ ).

It was evident from Table (1) that $43.3 \%$ and $76.7 \%$ respectively of children in both groups their age ranged from 1 year to less than three years.
Two fifth of children in both groups were ranked as the first child in their families. There was no statistically significant difference between children in both groups regarding age and rank in the family $\left(\mathrm{X}^{2}=2.589, p=.629, \mathrm{X}^{2}=0.370, p=.543 \& \mathrm{X}_{2}=\right.$ $14.694, p=.100$, respectively).

Table (2) clarified that the highest percentage of children had 2 nd degree hypospadias in both groups (73 .3\% \& 66.7, respectively). An equal percentage $(13.3 \%)$ of children in both groups had a family history of hypospadias. As regards family member who had hypospadias, it was found that half of family members $(50 \%)$ who had hypospadias in the study group were uncles. On the other hand, half of family members $(50 \%)$ who had hypospadias in the control group were fathers and the other $50 \%$ were brothers.

Table (3) reflected that the site of urethral meatus was distal among $66.7 \%$ of children in the study group compared to $60 \%$ among children in the control group. Regarding to the prepuce, it was incomplete among $76.7 \%$ of children in the study group and $60 \%$ of children in the control group. In relation to glans of penis, it was incomplete cleft in more than two thirds in children of both groups $(73.3 \%$ \& $66.7 \%$, respectively). There was penile torsion among $86.7 \%$ of children in the study group and $66.7 \%$ of children in the control group. There was no statistically significant difference between children in both groups regarding preoperative observational records as: site of urethral meatus, prepuce, glans penis and penile tor$\operatorname{sion}\left(\mathrm{X}^{2}=2.217, p=.988, \mathrm{X}_{2}=0.497, p=.481, \mathrm{X}_{2}=\right.$ $3.835, p=.994 \& X_{2}=3.606, p=.058$, respectively).

It was clear from Table (4) that $66.7 \%$ and $53.3 \%$ respectively of children in both groups had moderate hypospadias. As regards circumcision, the study results proved that $90 \%$ and $80 \%$ respectively of children in both groups were not circumcised. Regarding to administration of preparative hormonal therapy, it was found that $23.3 \%$ and $13.3 \%$ respectively of children in groups took hormonal therapy.

Table (5) proved that the mean of the total score of mothers' knowledge about hypospadias before implementation of nursing instructions in the study group was $2.40 \pm 1.71$ and $2.70 \pm 1.48$ for those in control group. All mothers in both groups had unsatisfactory level of knowledge in the pretest. After implementation of nursing instructions, the total mean score of mothers' knowledge about hypospadias in the study group was $32.77 \pm 0.43$ 
compared to $8.97 \pm 1.71$ among mothers of children in the control group. All mothers in the study group had satisfactory level of knowledge in the posttest, while all mothers in control group still had unsatisfactory level. There was statistically significance difference between the total mean score of mothers' knowledge after implementation of nursing instructions in both groups $(t=-71.351, p=.<0.01)$.

Table (6) showed that children in the study group were exposed to postoperative bleeding less than children in the control group $(36.7 \%$ \& $73.3 \%$ respectively). It was found that $26.7 \%$ of children in the study group had mild bleeding increased to $56.7 \%$ among those in the control group. Children of the study group had elevated body temperature less than those in the control group $(53.3 \%$ \& $66.7 \%$, respectively).

Table (7) highlighted that an equal percentage $(90 \%)$ of children in both groups were experienced bruising as early complications. All children in the study group not exposed to postoperative wound dehiscence compared to $10 \%$ of children in the control group. Urinary obstruction occurred among children of the study group less than those in the control group ( $13.3 \%$ \& $26.7 \%$ in order). Also $47.7 \%$ and $40 \%$ respectively of children in both study and control group complained from postoperative burning urination. There was statistically significant difference between children in both groups regarding wound dehiscence $\left(\mathrm{X}_{2}=19.200\right.$, $p=<0.01)$.

Table (8) clarified that fistula occurred to children in the study group less than children in the control group (10\% \& $26.7 \%$, in order). Meatal stenosis and urethral stricture didn't occur to any child in the study group compared to children in the control group (3.3\% \& $13.3 \%$, respectively). Children in the study group complained of wound infection less than children in the control group (33.3\% \& 53.3\%, in order). There was statistically significant difference between children in both groups regarding meatal stenosis and urethral stricture $\left(\mathrm{X}^{2}=26.133, p=.000 \& \mathrm{X}^{2}=16.133\right.$, $p=<0.01$, respectively). Fig. (2) illustrated that the majority of children in the study group $(90 \%)$ had one direction of urine stream compared to $40 \%$ of children in the control group.

The current study results demonstrated that child's age, rank within the family and number of siblings had no statistically significant correlation with the occurrence of postoperative complications that need $2^{\text {nd }}$ operation among children in the study group.
Table (1): Percentage distribution of personal characteristics of children in study and control group.

\begin{tabular}{llllllll}
\hline \multirow{2}{*}{$\begin{array}{l}\text { Child's } \\
\text { characteristics }\end{array}$} & \multicolumn{2}{c}{$\begin{array}{c}\text { Study } \\
(\mathrm{n}=30)\end{array}$} & \multicolumn{2}{c}{$\begin{array}{c}\text { Control } \\
(\mathrm{n}=30)\end{array}$} & \multirow{2}{*}{$\mathrm{X}^{2}$} & $p$ \\
\cline { 2 - 5 } & $\mathrm{N}$ & $\%$ & $\mathrm{~N}$ & $\%$ & & \\
\hline $\begin{array}{l}\text { Child's age/years: } \\
\quad \text { < one year }\end{array}$ & 5 & 16.7 & 2 & 6.6 & 2.589 & .629 \\
$\quad$ 1 to less than 3 & 13 & 43.3 & 23 & 76.7 & & \\
$\quad$ 3 to less than 5 & 12 & 40 & 5 & 16.7 & & \\
Child's rank in & & & & & & \\
the family: & & & & & & \\
$\quad$ First & 12 & 40 & 12 & 40 & 14.694 & .100 \\
$\quad$ Second & 5 & 16.7 & 11 & 36.7 & & \\
$\quad$ Third & 6 & 20 & 5 & 16.7 & & \\
$\quad$ More than third & 7 & 23.3 & 2 & 6.6 & & \\
\hline
\end{tabular}

Table (2): Percentage distribution of data related to diagnosis among children of study and control group.

\begin{tabular}{|c|c|c|c|c|c|c|}
\hline \multirow[t]{2}{*}{ Items } & \multicolumn{2}{|c|}{$\begin{array}{l}\text { Study } \\
(\mathrm{n}=30)\end{array}$} & \multicolumn{2}{|c|}{$\begin{array}{c}\text { Control } \\
(n=30)\end{array}$} & \multirow[t]{2}{*}{$X^{2}$} & \multirow[t]{2}{*}{$p$} \\
\hline & $\mathrm{N}$ & $\%$ & $\mathrm{~N}$ & $\%$ & & \\
\hline \multicolumn{7}{|l|}{ Diagnosis: } \\
\hline $\begin{array}{l}\text { Hypospadias } 1 \text { st } \\
\text { degree }\end{array}$ & 3 & 10 & 6 & 20 & 3.826 & .430 \\
\hline $\begin{array}{l}\text { Hypospadias } 2 \mathrm{nd} \\
\text { degree }\end{array}$ & 22 & 73.3 & 20 & 66.7 & & \\
\hline $\begin{array}{l}\text { Hypospadias } 3^{\text {rd }} \\
\text { degree }\end{array}$ & 5 & 16.7 & 4 & 13.3 & & \\
\hline \multicolumn{7}{|l|}{$\begin{array}{l}\text { Family history of } \\
\text { hypospadias: }\end{array}$} \\
\hline Yes & 4 & 13.3 & 4 & 13.3 & 0.710 & .399 \\
\hline No & 26 & 86.7 & 26 & 86.7 & & \\
\hline
\end{tabular}

Table (3): Pre-operative observations for children in study and control group.

\begin{tabular}{|c|c|c|c|c|c|c|}
\hline \multirow{2}{*}{ Items } & \multicolumn{2}{|c|}{$\begin{array}{c}\text { Study } \\
(\mathrm{n}=30)\end{array}$} & \multicolumn{2}{|c|}{$\begin{array}{c}\text { Control } \\
(\mathrm{n}=30)\end{array}$} & \multirow{2}{*}{$X^{2}$} & \multirow[t]{2}{*}{$p$} \\
\hline & $\mathrm{N}$ & $\%$ & $\mathrm{~N}$ & $\%$ & & \\
\hline \multicolumn{7}{|c|}{ Site of urethral meatus: } \\
\hline Glandular & 3 & 10 & 6 & 20 & 2.217 & .988 \\
\hline Distal & 20 & 66.7 & 18 & 60 & & \\
\hline Proximal & 6 & 20 & 5 & 16.7 & & \\
\hline Perineal & 1 & 3.3 & 1 & 3.3 & & \\
\hline \multicolumn{7}{|l|}{ Prepuce: } \\
\hline Complete & 7 & 23.3 & 12 & 40 & 0.497 & .481 \\
\hline Incomplete & 23 & 76.7 & 18 & 60 & & \\
\hline \multicolumn{7}{|l|}{ Glans: } \\
\hline Cleft & 4 & 13.3 & 2 & 6.7 & 3.835 & .429 \\
\hline Incomplete cleft & 22 & 73.3 & 20 & 66.7 & & \\
\hline Flat & 4 & 13.3 & 8 & 26.7 & & \\
\hline
\end{tabular}


Table (4): Pre-operative observations for children in study and control group, cont.

\begin{tabular}{|c|c|c|c|c|c|c|}
\hline \multirow[t]{2}{*}{ Items } & \multicolumn{2}{|c|}{$\begin{array}{c}\text { Study } \\
(\mathrm{n}=30)\end{array}$} & \multicolumn{2}{|c|}{$\begin{array}{c}\text { Control } \\
(\mathrm{n}=30)\end{array}$} & \multirow[t]{2}{*}{$X^{2}$} & \multirow[t]{2}{*}{$p$} \\
\hline & $\mathrm{N}$ & $\%$ & $\mathrm{~N}$ & $\%$ & & \\
\hline $\begin{array}{l}\text { Severity of hypospadias: } \\
\text { Mild } \\
\text { Moderate } \\
\text { Severe }\end{array}$ & $\begin{array}{l}3 \\
20 \\
7\end{array}$ & $\begin{array}{l}10 \\
66.7 \\
23.3\end{array}$ & $\begin{array}{l}8 \\
16 \\
6\end{array}$ & $\begin{array}{l}28.7 \\
53.3 \\
20\end{array}$ & 1.205 & .877 \\
\hline $\begin{array}{l}\text { Circumcision: } \\
\text { Done } \\
\text { Not done }\end{array}$ & $\begin{array}{l}3 \\
27\end{array}$ & $\begin{array}{l}10 \\
90\end{array}$ & $\begin{array}{l}6 \\
24\end{array}$ & $\begin{array}{l}20 \\
80\end{array}$ & 0.370 & .543 \\
\hline $\begin{array}{l}\text { Types of preoperative } \\
\text { medications given to } \\
\text { children: } \\
\text { None } \\
\text { Antibiotics } \\
\text { Hormonal therapy }\end{array}$ & $\begin{array}{l}20 \\
2 \\
7\end{array}$ & $\begin{array}{l}66.7 \\
6.7 \\
23.3\end{array}$ & $\begin{array}{l}15 \\
8 \\
4\end{array}$ & $\begin{array}{l}50 \\
26.7 \\
13.3\end{array}$ & 8.163 & .518 \\
\hline
\end{tabular}

Table (5): Comparison between total mean score of mothers' knowledge before and after implementation of nursing instructions in both study and control group.

\begin{tabular}{lcccc}
\hline \multirow{2}{*}{ Items } & $\begin{array}{c}\text { Study } \\
(\mathrm{n}=30)\end{array}$ & $\begin{array}{c}\text { Control } \\
(\mathrm{n}=30)\end{array}$ & $t$ & \\
\cline { 2 - 3 } & $\mathrm{N} \%$ & $\mathrm{~N} \%$ & & \\
\hline
\end{tabular}

Mothers' knowledge

before implementa-

tion of nursing

instructions:

$\begin{array}{lllllll}\text { Satisfactory } & 0 & 0 & 0 & 0 & 0.850 & .402\end{array}$

Unsatisfactory $\quad 30 \quad 100 \quad 30 \quad 100$

Mean \pm SD $\quad 2.40 \pm 1.71 \quad 2.70 \pm 1.48$

Mothers' knowledge

after implementa-

tion of nursing

instructions:

$\begin{array}{lllllll}\text { Satisfactory } & 30 & 100 & 0 & 100 & -71.351 & .000^{*} \\ \text { Unsatisfactory } & 0 & 0 & 30 & 0 & & \\ \text { Mean } \pm \text { SD } & 32.77 \pm 0.43 & 8.97 \pm 1.71 & & \end{array}$

*Significant at $p<0.01$.

Table (6): Postoperative outcomes (early complications) among children in study and control groups.

\begin{tabular}{|c|c|c|c|c|c|c|}
\hline \multirow{2}{*}{ Item } & \multicolumn{2}{|c|}{$\begin{array}{l}\text { Study } \\
(\mathrm{n}=30)\end{array}$} & \multicolumn{2}{|c|}{$\begin{array}{c}\text { Control } \\
(\mathrm{n}=30)\end{array}$} & \multirow[t]{2}{*}{$X^{2}$} & \multirow[t]{2}{*}{$p$} \\
\hline & $\mathrm{N}$ & $\%$ & $\mathrm{~N}$ & $\%$ & & \\
\hline $\begin{array}{l}1^{\text {st }} \text { postoperative day } \\
\text { complications } \\
\text { (bleeding): }\end{array}$ & & & & & & \\
\hline $\begin{array}{l}\text { Yes } \\
\text { No }\end{array}$ & $\begin{array}{l}11 \\
19\end{array}$ & $\begin{array}{l}36.7 \\
63.3\end{array}$ & $\begin{array}{l}22 \\
8\end{array}$ & $\begin{array}{l}73.3 \\
26.7\end{array}$ & 0.835 & .361 \\
\hline $\begin{array}{l}\text { Severity of bleeding: } \\
\text { None } \\
\text { Mild } \\
\text { Moderate } \\
\text { Severe }\end{array}$ & $\begin{array}{l}19 \\
8 \\
2 \\
1\end{array}$ & $\begin{array}{l}63.3 \\
26.7 \\
6.7 \\
3.3\end{array}$ & $\begin{array}{l}8 \\
17 \\
5 \\
0\end{array}$ & $\begin{array}{l}26.7 \\
56.7 \\
16.7 \\
0\end{array}$ & 4.978 & .547 \\
\hline $\begin{array}{l}\text { Thirdpostoperative day } \\
\text { complications (fever): } \\
\text { Normal temperature } \\
\text { Above normal } \\
\text { Below normal }\end{array}$ & $\begin{array}{l}16 \\
14 \\
0\end{array}$ & $\begin{array}{l}53.3 \\
46.7 \\
0\end{array}$ & $\begin{array}{l}20 \\
10 \\
0\end{array}$ & $\begin{array}{l}66.7 \\
33.3 \\
0\end{array}$ & 1.674 & .196 \\
\hline
\end{tabular}

Table (7): Postoperative outcomes (early complications) among children in study and control group, cont.

\begin{tabular}{|c|c|c|c|c|c|c|}
\hline \multirow[t]{2}{*}{ Item } & \multicolumn{2}{|c|}{$\begin{array}{l}\text { Study } \\
(n=30)\end{array}$} & \multicolumn{2}{|c|}{$\begin{array}{c}\text { Control } \\
(n=30)\end{array}$} & \multirow[t]{2}{*}{$\mathrm{X} 2$} & \multirow[t]{2}{*}{$p$} \\
\hline & $\mathrm{N}$ & $\%$ & $\mathrm{~N}$ & $\%$ & & \\
\hline \multicolumn{7}{|l|}{ Bruising: } \\
\hline Present & 27 & 90 & 27 & 90 & 0.370 & .543 \\
\hline Not present & 3 & 10 & 3 & 10 & & \\
\hline \multicolumn{7}{|l|}{ Wound dehiscence: } \\
\hline Present & 0 & 0 & 3 & 10 & 19.200 & $p<0.01 *$ \\
\hline Not present & 30 & 100 & 27 & 90 & & \\
\hline \multicolumn{7}{|l|}{ Urinary obstruc- } \\
\hline Present & 4 & 13.3 & 8 & 26.7 & 1.285 & 257 \\
\hline Not present & 26 & 86.7 & 22 & 73.3 & & \\
\hline \multicolumn{7}{|l|}{$\begin{array}{l}\text { Other complica- } \\
\text { tions: }\end{array}$} \\
\hline 1- None & 14 & 46.7 & 15 & 50 & 7.929 & .094 \\
\hline $\begin{array}{l}\text { 2- Burning } \\
\text { urination }\end{array}$ & 14 & 46.7 & 12 & 40 & & \\
\hline $\begin{array}{l}\text { 3- Urinary } \\
\text { catheter fall }\end{array}$ & 2 & 6.6 & 3 & 10 & & \\
\hline
\end{tabular}

*Significant at $p<0.01$

Table (8): Postoperative outcomes (late complications) among children in study and control groups.

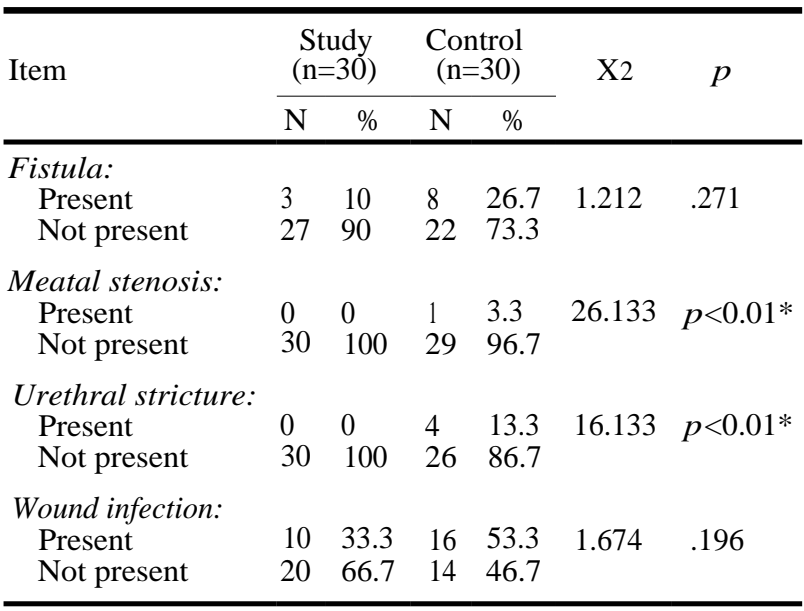

*Significant at $p<0.01$.

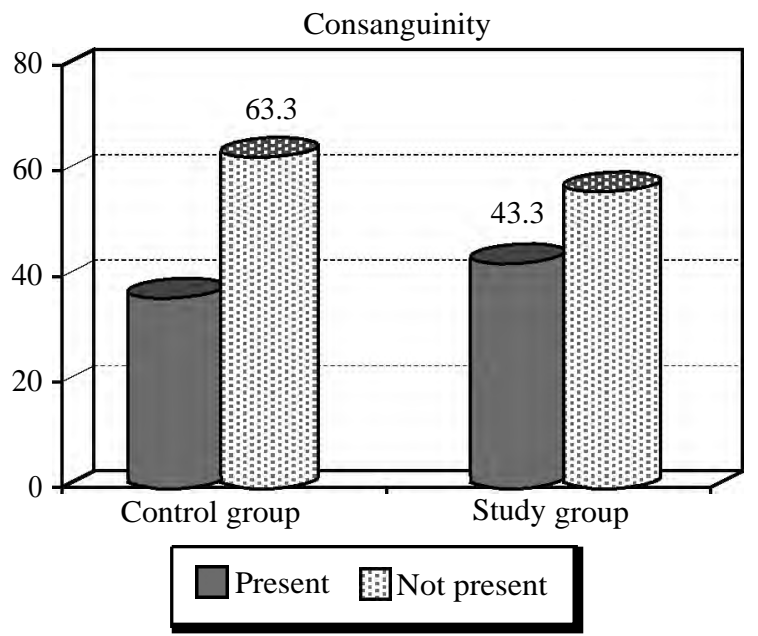

Fig. (1): Consanguinity among mothers in both study and control groups. 


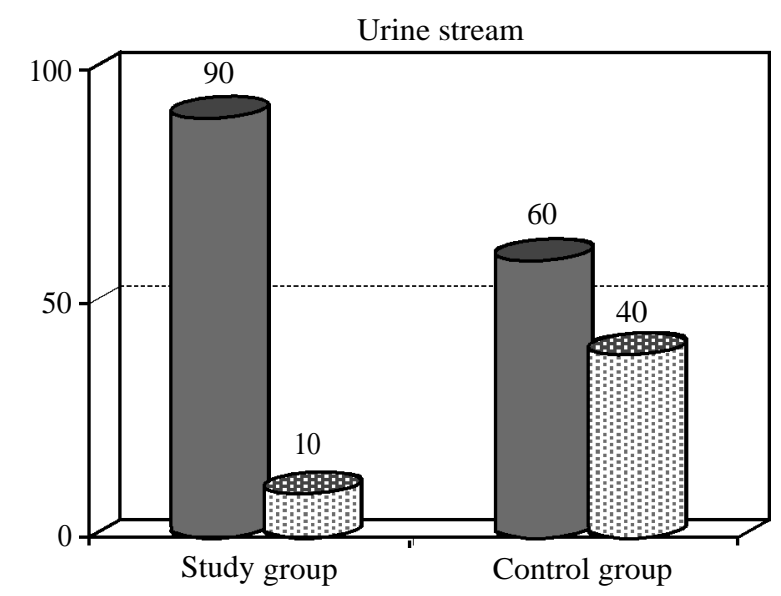

One direction of urine stream
Interrupted direction of urine stream

Fig. (2): Postoperative outcomes (functional outcome), among children in study and control groups.

\section{Discussion}

The results of the current study indicated that the highest percentage of mothers in both groups their age ranged from 25 to less than 30 years. This result congruent with [16] that studied geographic analysis of individual and environmental risk factors for hypospadias births and found that $27.6 \%$ of mother's aged was from 25 to less than 30 years. These factors could be associated with mother's response to health education as regard to postoperative outcome.

As regards to mothers' level of education; the current study revealed that half of mothers in the study group were not read or write while, more than one third of mothers in the control group had basic education. This result found higher literacy rate among mothers in the control than in the study group. On the same line, [17] assured that, the literacy rate among females was $65.4 \%$ compared to $63.5 \%$ 2012. So efforts of governmental and non-governmental organizations should continue to focus on female' education because low levels of literacy, and education in general, can impede the economic development of a country in the current rapidly changing, technology-driven world, this of course will reflect positively on the health care system as a whole.

Early hypospadias surgery may be associated with better long-term outcomes (better outcomes with younger aged children). The results of the current study were in accordance to the above mentioned empirical evidences and demonstrated that the highest percentage of children in both groups their age ranged from 1 year to less than three years [18]. On the same line, in a recent Egyptian study held by [19] about Tubularized incised-plate versus tubularization of an intact and laterally augmented plate for hypospadias repair among 370 child, they found that the mean age for children's in both groups was 2.8 year and 2.5 year respectively.

The current study clarified that the highest percentage of children had 2 nd degree hypospadias in both groups. This result corresponded to [19] who found that the highest percentage of children had 2 nd degree hypospadias in both groups (49.4\% coronal \& $45.2 \%$ sub coronal, respectively). On the same line, [18] concluded that $92 \%$ of children had $2^{\text {nd }}$ degree hypospadias and had a single procedure repair.

As well, [20] conducted a study about hypospadias among children admitted to pediatric surgical unit in Alexandria University hospital. The study focused on types and surgical management on 1087 child with hypospadias. The study results summarized that the most frequent type of hypospadias (35.6\%) was 2 nd degree hypospadias (sub coronal) followed by glandular type (29.25\%) and the least type diagnosed was penoscrotal $1.29 \%$.

The current study indicated that the minority of children in both groups had a family history of hypospadias. These result concurrent with [21] who indicated that about seven percent of children with hypospadias have other sibling with the same issue. On the same context, [22] conducted a study to explore the prevalence and risk factors of hypospadias in Northeast Iran and found that positive family history was present in $44 \%$ of cases in hypospadias group.

The current study reflected that the site of urethral meatus was distal in more than two thirds of children in the study group compared to less than two third among children in the control group. In a similar Egyptian study conducted by [23] reported that about half of children who included in the study had distal hypospadias. In a retrospective study done by [24] on 474 children undergoing primary hypospadias surgery, it was found that $77.2 \%$ of children had distal hypospadias.

In relation to the prepuce, it was incomplete in more than three quarters of children in the study group and in more than half of children in the control group. These results support current evidence by [25] who pointed out that $95 \%$ of children with hypospadias have incomplete prepuce. These results also consistent with [26] and [27] whose 
opinion was that hypospadias is combined by incomplete foreskin (prepuce) in most male children with hypospadias. In relation to glans of penis, it was incomplete cleft in more than two thirds in children of both groups. In the same line, [28] found that all children participated in the study had flat or incomplete cleft glans.

It was evident that there was penile torsion among the majority of children in the study group and just more than two thirds of children in the control group. In contrast, [6] on their study to correlate the severity of penile torsion with type of hypospadias and ventral penile curvature and their management, found that $30.8 \%$ of children had penile torsion. A burgeoning literature by [29] has also mentioned that penile torsion is a subject of interest that occurs in little with hypospadias but can be isolated anomaly.

As regards the severity of hypospadias, the current study results showed that the highest percentage of children in both groups had moderate hypospadias. Similarly [30] conducted epidemiological assessment of hypospadias by degree of severity and found that $60.7 \%$ of children had mild hypospadias. Concerning circumcision, the study results proved that the majority of children in both groups were not circumcised. These results supported by several literatures by $[31,32]$ who emphasized that circumcision should be postponed to preserve foreskin for the surgical repair. Regarding to administration of preoperative hormonal therapy, it was found that the minority of children in both groups took hormonal therapy (topically hormonal stimulation to increase the penile size).

After implementation of the preoperative instructions, it was evident that all mothers of children with hypospadias in the study group had satisfactory level of knowledge. While, $100 \%$ of mothers of children in the control group still have unsatisfactory level of knowledge. A statistically significant difference was detected between the total mean scores of mothers in both groups as regards care of their children with hypospadias. These results indicate the effectiveness of the nursing instructions on improving mothers' knowledge in the study group.

In a recent Egyptian study by [33] to investigate the effect of pre-designed instructions for 60 mothers of children with hypospadias on reducing postoperative complications, it was found that the majority (90\%) of mothers in the control group and all in the study group had inadequate level of knowledge about hypospadias in pre-test.
As regards postoperative outcomes (early complications) among children in both groups, the current study showed that children in study group were exposed to postoperative bleeding less than children in the control group. In contrast, a recent study held by [34] on 70 child to compare tourniquet application and epinephrine injection for homeostasis during hypospadias surgery in terms of bleeding and complications. It was found that no child in tourniquet group and only $3 \%$ of children in epinephrine group had postoperative bleeding.

Regarding fever at the third postoperative day, the study results revealed that children of the study group had elevated body temperature less than those in the control group. These results correspond with [39 who mentioned that fever above $38^{\circ} \mathrm{C}$ is common in the first few days after major surgery. Most early postoperative mild fever is caused by the inflammatory stimulus of surgery and resolves spontaneously.

The majority of children in both groups were experienced bruising as early postoperative complication in the current study. On the same context, [36] in their study to introduce a new method of dressing in hypospadias surgery for 61 children, the study results concluded that $100 \%$ of children in both groups (group used conventional dressing and group used Cyanoacrylate glue dressing) had postoperative penile edema.

The current results revealed that no child in the study group exposed to postoperative wound dehiscence. The study results were supported by [37] who conducted study to evaluate the effects of parenteral testosterone administration on the results of hypospadias repair in 182 children. They found that no child in the study group exposed to postoperative wound dehiscence, while, $1.1 \%$ of children in the control group exposed to wound dehiscence.

It was evident that urinary obstruction occurred among children in the study group less than children in the control group. In the same line, [38] mentioned that the main causes of urinary obstruction are torsion or bending of the urinary catheter, sometimes it is difficult to maintain catheter patency. [39] Stated that stop of urinary drainage for more than 1 hour may be caused by kinking of the system or obstruction by sediment.

Postoperative painful urination and pain around bladder (bladder spasm) is common at first 3 days due to catheter or stent insertion this can be relieved by pain relieving measures. The results of the current study were in accordance to the above 
mentioned empirical evidences and demonstrated that $47.7 \%$ and $40 \%$ respectively of children in both groups complained from postoperative painful urination [40]

As regards to late complications, the current study evidenced that fistula occurred among children in the study group less than children in the control group. Several previous studies have shown that fistula is commonly happen post hypospadias repair such as [19] in Egypt found that both groups of TIP repair and laterally augmented plate repair had fistula $9.8 \% \& 2.8 \%$ respectively. Besides, [37] found that both control groups (took testosterone) and study group (didn't take testosterone) had fistula $4.4 \%$ \& $7.7 \%$, respectively.

The current study represented that children in the study group complained from signs of wound infection less than those in the study group. On the same context, [41] found that infection happened in group of two doses antibiotic less than group of one dose antibiotic ( $4 \% \& 5 \%$, respectively). As shown from the above mentioned results, children in the study group exposed to less postoperative complications than children in the control group. These results support the first hypothesis of the current study.

Regarding to the cosmetic appearance of the penis the results of the current study showed the majority of children in the study group the shape meatus was slit like shape compared to $70 \%$ of children in the control group. All children in the study group and the vast majority of children in the control group experienced postoperative ventral aspect of glans. Regarding to glans of the penis, it was found that children in the study group experienced acorn shaped glans, more than of children in the control group. As regards penile skin, children in the study group experienced evenly covered penile skin more than children in the control group.

As shown from the above mentioned results, children in the study group had appropriate cosmetic appearance of the penis more than those in the control group. With appropriate care provided to children through the preoperative nursing instructions given to the mothers, postoperative complications were avoided and so reach high satisfactory cosmetic appearance of the penis. These results support the third hypothesis of the current study.

In relation to the functional outcomes the current study results illustrated that the majority of children in the study group had one direction of urine stream compared to $40 \%$ of children in the control group.
Similarly, [42] found that $91 \%$ of children had one direction of urine stream after repair of hypospadias. As illustrated in the above mentioned results, children in the study group had improved urinary functional outcome than children in the control group. These results support the second hypothesis of the current study.

\section{Conclusion:}

The results of the current study concluded that after implementation of the preoperative instructions, there was significant improvement in the level of knowledge among mothers in study group. Children in the study group exposed to less early postoperative complications such as (bleeding, wound dehiscence, urinary obstruction and urinary catheter fall) than children in the control group. Late postoperative complications (fistula, meatal stenosis, urethral obstruction and infection) occurred in children in the study group less than those in the control group. Children in the study group had appropriate cosmetic appearance of the penis and improved functional outcome than children in the control group.

\section{Recommendations:}

Based on the results of the current study, it was recommended that:

- Raising the awareness of pediatric surgical nurses through in-service training sessions about the benefits of giving preoperative teaching to the mothers of children with hypospadias is mandatory on improving the postoperative outcomes of those children.

- Simple Arabic illustrated booklet about preoperative and postoperative care for children undergoing surgical repair of hypospadias should be available in every pediatric surgical ward.

- Multidisciplinary team should be involved in developing, implementing and evaluating educational sessions for mothers of children with hypospadias to achieve better postoperative outcomes for children.

- Longitudinal study is necessary to monitor the late postoperative complications and long term outcomes.

\section{References}

1- AVILE L.A. and MALDONADO L.A.: Risk factors, prevalence trend and clustering of hypospadias cases in Puerto Rico. Journal of Pediatric Urology, 2014: 10761082, 2016.

2- METZLER L., NGUYEN H., HAGANDER L., JALLOH M., NGUYEN T. , GUEYE S.M., VRIES C. and MEARA J.: Surgical Outcomes and Cultural Perceptions in Inter- 
national Hypospadias Care. American Urological Association Education and Research, 192: 524-529, 2014.

3- ORTQVIST L., FOSSUM M., ANDERSSON M., NORDENSTREOM M., FRISEN L., HOLMDAHL G. and NORDENSKJEOLD A.: Long-Term follow-up of Men Born with Hypospadias: Urological and Cosmetic Results. The Journal of Urology, 193: 975-982, 2015.

4- SHIH E.M. and GRAHAM J.M.: Review of genetic and environmental factors leading to hypospadias. European Journal of Medical Genetics, 57: 453-463, 2016.

5- AMERICAN ACADEMY of PEDIATRIC.: Hypospadias. Available at www.healthychildren.org, 2012.

6- BHAT A., SABHARWAL K., BHAT M., SINGLA M., UPADHAYA R. and KUMA V.: Correlation of severity of penile torsion with type of hypospadi as and ventral penile curvature and their management. African Journal of Urology, 177: 1-8, 2015.

7- FRAUMANN S., STEPHANY H., CLAYTON B., THOMAS J., PORE J., ADAMS M., BROCK J. and TANAKA S.: Long-term follow-up of children who underwent severe hypospadias repair using an online survey with validated questionnaires. Journal of Pediatric Urology, 10: 446450. 2014

8- EKINCI S., ZDEN C.A., KARNAK I., EMIN M. and ENOCAK S.: Eccentric circummeatal based flap with limited urethral mobilization: An easy technique for distal hypospadias repair. Journal of Pediatric Urology, 12: 116.e1-116.e6, 2016.

9- SALLE J.L., SAYED S., SALLE A., BAGLI D., FARHAT W., KOYLE M. and LORENZO A.J.: Proximal hypospadias: A persistent challenge. Single institution outcome analysis of three surgical techniques over a 10 year period. Journal of Pediatric Urology, 12: 28.e1-28.e7, 2016.

10- CHEN C., YANG T., CHEN J., SUN N. and ZHANG W.: The effect of staged transverse preputial island flap urethroplasty for proximal hypospadias with severe chordee. The journal of Urology, 1: 1-13, 2016.

11-DELANEY D., BAYLEY E., OLSZEWSKY P. and GALLAGHER J.: Parental Satisfaction with Pediatric Preoperative Assessment and Education in a Pre-surgical Care Center. American Society of Perioperative-Anesthesia Nurses, 30 (4): 290-300, 2015.

12- MEYER C., SUKUMAR S., SOOD A., HANSKE J., VETTERLEIN M., ELDER J.S., FISCH M., TRINH Q.D. and FRIEDMAN A.A.: Inpatients hypospadias care: Trends and outcomes from the American nationwide inpatient sample. Korean Journal of Urology, 56: 594600,2015

13- BALL J., BINDLER R. and COWEN K.: Child Health Nursing Partnering with Children and Families. USA. Pearson, $2^{\text {nd }}$ ed. pp. 13 15-13 17, 2014.

14- THE INSTITUTE OF PEDIATRIC UROLOGY. Available at https://www.cornellurology.com, 2014.

15- STATISTICAL DEPARTMENT AT CAIRO UNIVERSITY (CUSPH), 2014.

16- WINSTON J.J., MEYER R.E. and EMCH M.E.: Geographic Analysis of Individual and Environmental Risk Factors for Hypospadias Births. Birth Defects Research (Part A), 100 (11): 887-894, 2014.
17- EGYPT DEMOGRAPHIC PROFILE. Available at www.indexmundi.com/egypt/demographics profile.html. 2015.

1 8- LU Y., HUANG W., CHEN Y., CHANG H., PONG Y., SHIN T. and HUANG K.: Factors associated with reoperative in hypospadias surgery- A nationwide, populationbased study. Asian Journal of Surgery, 2: 1-7, 2015.

19- ELBAKRY A., HEGAZY M., MATAR A. and ZAKARIA A.: Tubularized incised-plate versus tubularization of an intact and laterally augmented plate for hypospadias repair: A prospective randomized study. Arab Journal of Urology, 1-8, 2016.

20- MOHAMMED F.S., WAHEED S.M., ASHOUR A.S. and ASHRY M.S.: Hypospadias among children presented to pediatric surgical unit in Alexandria University hospital from year 2009 to 2014 types and surgical management. Doctorate thesis, 2016.

21- MANSKI D.: Hypospadias causes, diagnosis and treatment. Available at www.urology-textbook.com/hypospadia, 2016

22- ZADEH A.M., FARHAT A., ESMAIELI H. and SHIRANZAEI S.: Prevalence and risk factors of hypospadias in a private hospital in Northeast Iran. Iranian Journal of Pediatrics, 21 (4): 491-501, 2011.

23- ELGANAINY E.O.: A modified Onlay island flap vs Mathieu urethroplasty for distal hypospadias repair: A prospective randomized study. Arab Journal of Urology, 13: 169-175, 2015

24- SPINOIT A.O., POELAERT F., PRAET C.V., GROEN L., LAECKE E.V. and HOEBEKE P.: Grade of hypospadias is the only factor predicting for re-intervention after primary hypospadias repair: A multivariate analysis from a cohort of 474 patients. Journal of Pediatric Urology, 11: 70e1-70e6, 2015.

25- HADIDI A.: Hypospadias surgery. Available at www.hypospadias-online.com/engl faq 3.htm. 2016.

26- SINGAL A.K. : Goals of hypospadias repair surgery. Available at www.hypospadiasfoundation.com, 2014.

27- FRISBIE D.: Hypospadias: Surgery and circumcision. Available at www.drmomma.org, 2010

28- HADIDI A.: Proximal hypospadias with small flat glans: the lateral-based Onlay flap technique. Journal of Pediatric Surgery, 47 (11): 2151-2157, 2012.

29- MARCDANTE K. and KLIEGMAN R.: Nelson Essentials of Pediatrics. USA. Elsevier, $7^{\text {th }}$ ed. pp.568, 2015.

30- CANON S., MOSLEY B., CHIPOLLINI J. and Hobbs, C.: Epidemiological assessment of hypospadias by degree of severity. Urology, 188 (6): 1-6, 2012.

31- CEBTERS DISEASE CONTROL and PREVENTION (CDC). : Facts about Hypospadias. Available at www. cdc.com, 2016.

32- HOLCOMB G.W., MURPHY J. and OSTLIE D.: Ashcraft's Pediatric Surgery. USA Elsevier, 6th ed. pp.790, 2015.

33- AHMED S.M.: Effect of Pre-Designed Instructions for Mothers of Children with Hypospadias on Reducing Postoperative Complications. Journal of Education and Practice, 6 (5): 5-20, 2015. 
34- ALIZADEH F., FAKOOR A. and HAGHDANI S.: A comparison between tourniquet application and epinephrine injection for homeostasis during hypospadias surgery: The effect on bleeding and postoperative outcome. Journal of Pediatric Urology, 12: 160.e1-160.e5, 2016.

35- WEED H. and BADDOUR L.: Postoperative fever. Available at www.uptodate.com/contents/postoperative-fever. 2015.

36- HOSSEINI S.M., RASEKHI A.R., ZARENEZHAD M. and HEDJAZI A.: Cyanoacrylate glue dressing for hypospadias surgery. North American Journal of Medicine Science, 4 (7): 320-322, 2012.

37- ASGARI S.A., SAFARINEJAD M.R., POORREZA F., SAFAEI A., GHANAIE A.M. and SHAHAB E.: The effect of parenteral testosterone administration prior to hypospadias surgery: A prospective, randomized and controlled study. Journal of Pediatric Urology, 11: 143e1143e6, 2015.
38- GORNIAK M.: Hypospadias surgery-early and late complications. Available at http://marekgorniak.pl/en/spodziectwo-powik.html, 2016.

39- SILVESTRI L.A.: Comprehensive Review for the NCLEX$\mathrm{PN}{ }^{\circledR}$ Examination. Canada. Elsevier, $6^{\text {th }}$ ed. pp.428, 2013.

40- HEART M.H.: Post-operative instructions and home care after hypospadias repair surgery. Available at www.hypospadiasfoundation. c om, 2016.

41- ZEIAI S., NORDENSKJOLD A. and FOSSUM M.: Advantages of Reduced Prophylaxis after Tubularized Incised Plate Repair of Hypospadias. The Journal of Urology, 196 (4): 1244-1249, 2016

42- AL-ADL A.M., EL-KARAMANY T.M. and BASSIOUNY A.S.: Distal extension of the midline urethral-plate incision in the Snodgrass hypospadias repair: An objective assessment of the functional and cosmetic outcomes. Arab Journal of Urology, 12 (2): 116-126, 2014.

\section{تأثير إرشادات ما قبل الجراحة للأمهات على نتائج مختارة بعد الجراحة الجماحي

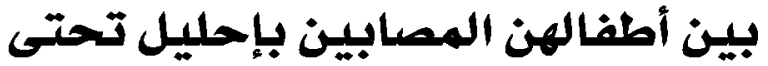

الإحليل التحتى هو عيب خلقى فى الأطفال البنين بحيث تكون فتحة البول لا تقع طرف القضيب. تتكن فتحة مجرى البول بشكل

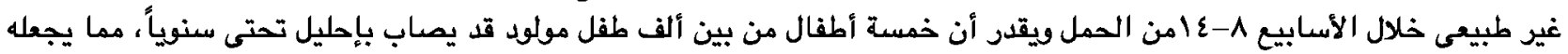

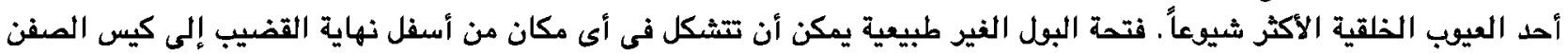

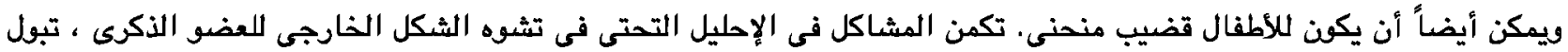

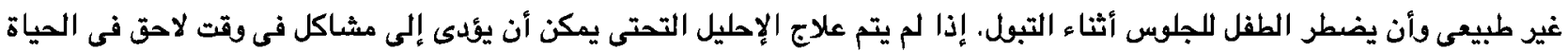

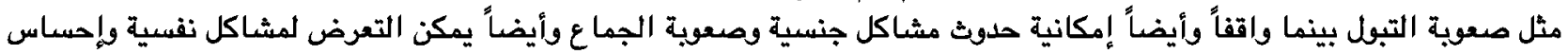
بعدم الثقة والآختلاف عن الآخرين.

كان هدف الدراسة الحالية تقييم تأثير إرشادات ما قبل الجراحة للأمهات على نتائج مختارة بعد الجراحة بين أطفالهن المصابين بإحليل تحتى.

استخلصست نتائج الدراسة الحالية إلى أنه بعد تنفيذ التعلميات قبل الجراحة كان هناك تحسن كبير بين الأمهات فى فريق الدراسية.

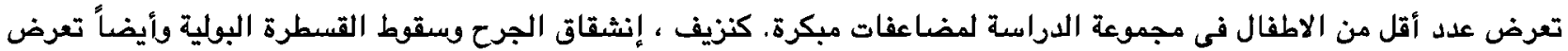
عدد أقل من الاطفال فى مجموعة الدراسة لمضاعفات متأخرة. حصل عدد أكبر من الاطفال فى مجموعة الدراسة لنتائج تجميلية ووظيفية 